\title{
A Novel Photocatalyst with Ferromagnetic Core Used for the Treatment of Olive Oil Mill Effluents from Two-Phase Production Process
}

\author{
Javier Miguel Ochando-Pulido, ${ }^{1}$ Gassan Hodaifa, ${ }^{2}$ \\ María Dolores Víctor-Ortega, ${ }^{1}$ and Antonio Martínez-Ferez ${ }^{1}$ \\ ${ }^{1}$ Chemical Engineering Department, University of Granada, 18071 Granada, Spain \\ ${ }^{2}$ Molecular Biology and Biochemical Engineering Department, University Pablo de Olavide, 14013 Seville, Spain
}

Correspondence should be addressed to Gassan Hodaifa; ghodaifa@upo.es

Received 26 August 2013; Accepted 2 October 2013

Academic Editors: F. Oktar and Z. Zhang

Copyright (C) 2013 Javier Miguel Ochando-Pulido et al. This is an open access article distributed under the Creative Commons Attribution License, which permits unrestricted use, distribution, and reproduction in any medium, provided the original work is properly cited.

\begin{abstract}
Photocatalytic degradation of olive oil mill wastewater from two-phase continuous centrifugation process was studied. A novel photocatalyst with ferromagnetic properties was characterized and investigated. The degradation capacity of the photocatalytic process of olive oil washing wastewater $(\mathrm{OMW})$ and mixture of olives and olive oil $(1 \mathrm{v} / \mathrm{v})$ washing wastewaters $(\mathrm{MOMW})$ was demonstrated. At lab-scale, the \%COD removal and residence time $(\tau)$ for MOMW and OMW were $58.4 \%(\tau=2 \mathrm{~h})$ and $21.4 \%$ $\left(\tau=3 \mathrm{~h}\right.$ ), respectively. On the other hand, at pilot scale, $23.4 \% \mathrm{COD}_{\text {removal }}, 19.2 \%$ total phenols removal , and $28.1 \%$ total suspended

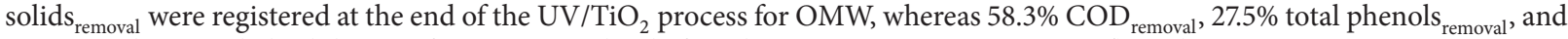
$25.0 \%$ total suspended solids removal $_{\text {for }} \mathrm{MOMW}$. Also, before the $\mathrm{UV} / \mathrm{TiO}_{2}$ reaction, a $\mathrm{pH}$-T flocculation operation as pretreatment was realized. The overall efficiency of the treatment process for MOMW was up to $91 \%$ of $\mathrm{COD}_{\text {removal }}$, in contrast with $33.2 \%$ of $\mathrm{COD}_{\text {removal }}$ for OMW.
\end{abstract}

\section{Introduction}

Photocatalysis with titanium dioxide $\left(\mathrm{TiO}_{2}\right)$ under ultraviolet light (UV) is an advanced oxidation process (AOP) in which the titanium dioxide semiconductor absorbs UV radiation and generates hydroxyl radicals $\left(\mathrm{OH}^{*}\right)$. In detail, conduction band electrons and valence band holes of $\mathrm{TiO}_{2}$ are initially yielded by UV irradiation. Thereafter, band electrons are capable of interacting with surface-adsorbed molecular oxygen to form superoxide radical anions $\left(\mathrm{O}_{2}{ }^{\circ}\right)$, whereas band holes will interact with water to produce hydroxyl radicals $\left(\mathrm{OH}^{*}\right)$ (Figure 1) [1]. Organic compounds can undergo oxidative degradation through their reactions with valence band holes, hydroxyl $\left(\mathrm{OH}^{*}\right)$, and superoxide $\left(\mathrm{O}_{2}{ }^{*}\right)$ radicals as well as reductive cleavage through their reactions with electrons $\left(\mathrm{e}^{-}\right)$.

The titanium dioxide molecule absorbs near UV radiation (wavelength $\lambda<400 \mathrm{~nm}$ ), leading to the generation of electron/valence band holes pairs, as indicated as follows (Figure 1):

$$
\mathrm{TiO}_{2}(h \cdot v) \longrightarrow \mathrm{TiO}_{2}\left(\mathrm{e}^{-}+\mathrm{h}^{+}\right)
$$

Valence band holes are prone to react with absorbed substances, in particular with water molecules $\left(\mathrm{H}_{2} \mathrm{O}_{\mathrm{ad}}\right)$ (2) or hydroxyl ions $\left(\mathrm{OH}^{-}{ }_{\text {ad }}\right)$ (3), generating hydroxyl radicals $\left(\mathrm{OH}^{*}\right)$ as follows:

$$
\begin{gathered}
\mathrm{TiO}_{2}\left(\mathrm{~h}^{+}\right)+\mathrm{H}_{2} \mathrm{O}_{\mathrm{ad}} \longrightarrow \mathrm{TiO}_{2}+\mathrm{OH}^{\bullet}+\mathrm{H}^{+} \\
\mathrm{TiO}_{2}\left(\mathrm{~h}^{+}\right)+\mathrm{OH}^{-}{ }_{\mathrm{ad}} \longrightarrow \mathrm{TiO}_{2}+\mathrm{OH}^{\bullet}
\end{gathered}
$$

Absorbed oxygen is the main electron acceptor species as follows:

$$
\mathrm{TiO}_{2}\left(\mathrm{e}^{-}\right)+\mathrm{O}_{2} \longrightarrow \mathrm{TiO}_{2}+\mathrm{O}_{2}^{\cdot}
$$

Among the known semiconductor photocatalysts $(\mathrm{ZnO}$, $\left.\mathrm{WO}_{3}, \mathrm{CdS}, \mathrm{ZnS}, \mathrm{SrTiO}_{3}, \mathrm{SnO}_{2}, \mathrm{Fe}_{2} \mathrm{O}_{3}\right) \mathrm{TiO}_{2}$ has deserved 


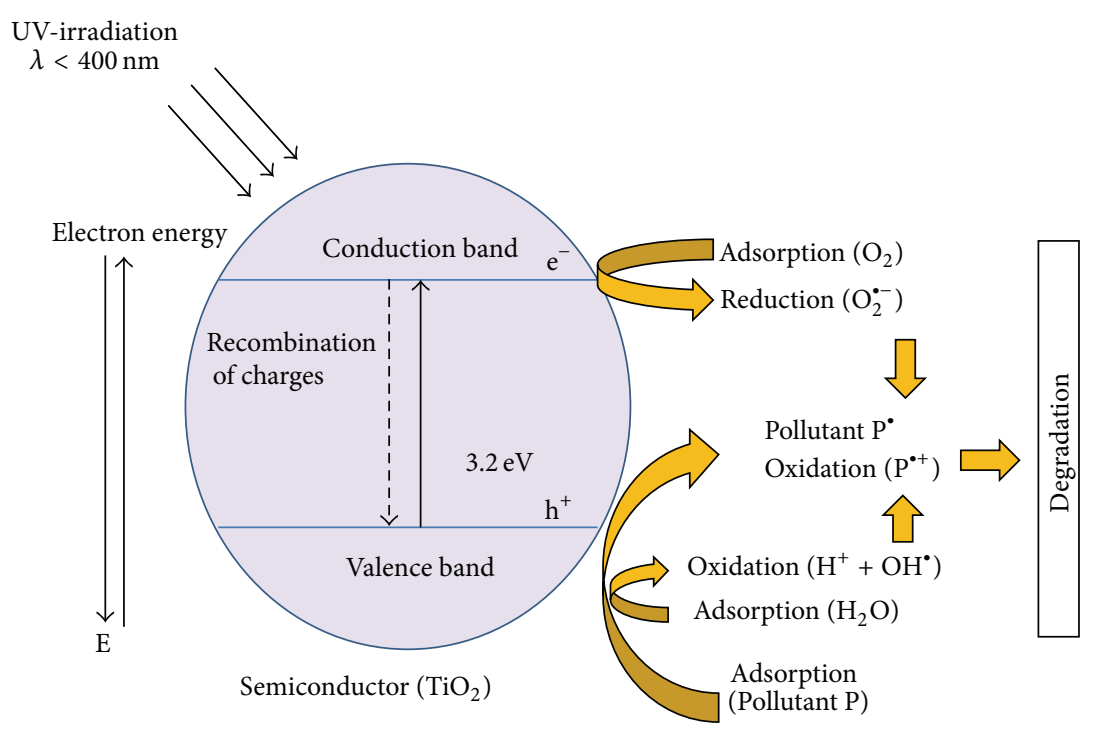

FIgURE 1: Activation of the $\mathrm{TiO}_{2}$ nanocatalyst by UV light.

particular interest owed to its high oxidizing power of organic contaminants along with its chemical stability and low cost [2]. The key advantages of $\mathrm{TiO}_{2} / \mathrm{UV}$ light photocatalysis process rely on the very high volume to surface ratio of titania nanoparticles that lead to the absence of mass transfer limitations when nanoparticles are used as photocatalysts, the possibility of being triggered at ambient operating conditions and to exploit sunlight instead of electric illumination in case of doped $\mathrm{TiO}_{2}$, and the fact that $\mathrm{TiO}_{2}$ is a highly active and nontoxic molecule capable of achieving complete mineralization of a wide range of organic pollutants or oxidizing them into harmless compounds [3, 4].

Olive oil factories, commonly known as olive mills, generate as by-product effluents (OME) an average daily amount of $1 \mathrm{~m}^{3}$ of wastewater derived from the washing of the olives (olives washing wastewater, OWW) together with more than $10 \mathrm{~m}^{3}$ of wastewater coming from the centrifugation process used for the extraction of the olive oil (olive oil mill wastewater, OMW). OMW exhibits a series of characteristics that make their reclamation by conventional physicochemical treatments extremely difficult. The presence of phytotoxic refractory pollutants, such as phenolic compounds, organic acids, tannins, long chain fatty acids, and organohalogenated contaminants, makes these effluents recalcitrant to biological degradation and thus inhibits the efficiency of biological processes. Moreover, the physicochemical composition of OMW is extremely variable as it depends on several factors such as the extraction process, edaphoclimatic, and cultivation parameters, as well as the type, quality, and maturity of the olives [5-7]. OMW typically exhibit strong odor nuisance, acid $\mathrm{pH}$, intensive violet-dark color, considerable saline toxicity reflected by high electroconductivity (EC) values, and very heavy organic pollutants load [5]. Additional difficulties such as small size and geographical dispersion of olive oil mills as well as seasonality of olive oil production are faced in the management of these agroindustry effluents.
In this research work, the treatment of the effluents generated by olive mills working with the two-phase olive oil extraction process (OMW-2) by $\mathrm{TiO}_{2} / \mathrm{UV}$ light photocatalysis is addressed. The aforementioned set of features highlight $\mathrm{TiO}_{2} / \mathrm{UV}$ light photocatalysis as a potential AOP from a technical and economical point of view if compared with other AOPs for the treatment of industrial effluents presenting high organic matter (COD) pollutants load [820]. However, the main handicap in applying photocatalytic processes for the reclamation of industrial and agrofood effluents relies in the cost of the catalyst. In this sense, the difficulty in recovering the catalyst poses the main technical-economical drawback. To solve this problem, a novel photocatalyst with ferromagnetic properties for ease of recovery and high effectiveness in the treatment of OMW2 was developed. Also, the evolution of the organic matter (COD) and degradation rates were determined.

\section{Experimental}

2.1. Feedstocks: Olive Oil Washing Wastewater (OMW) and Mixture of Olives and Olive Oil Washing Wastewater $(M O M W)$. Samples of OWW from the washing machines and OMW at the outlet of the vertical centrifuges were taken from an olive oil mill located in Jaén (Spain) operating with the modern two-phase olive oil extraction procedure [5]. Two different raw feedstocks were used for the present investigation: on one hand, OMW and on the other, a 1:1 $(\mathrm{v} / \mathrm{v})$ mixture of olives and olive oil washing wastewater (MOMW). The physicochemical characteristics of both raw feedstocks are reported in Table 1.

As it can be noted, the organic load in the effluent from the vertical centrifugation (OMW) is much higher than that from the washing of the olives (OWW) and MOMW, and the same occurs for the concentration of phenolic compounds 
TABLE 1: Raw OMW and MOMW physicochemical composition.

\begin{tabular}{lcc}
\hline Parameters & OMW & MOMW \\
\hline $\mathrm{pH}$ & $4.9-5.1$ & $5.9-6.3$ \\
Electric conductivity, $\mathrm{mS} \mathrm{cm}^{-1}$ & $1.76-1.84$ & $1.42-1.54$ \\
Total suspended solids, $\mathrm{g} \mathrm{L}^{-1}$ & $3.1-5.8$ & $6.1-6.9$ \\
$\mathrm{COD}, \mathrm{g} \mathrm{L}^{-1}$ & $16.4-16.6$ & $4.1-4.2$ \\
Total phenols, $\mathrm{g} \mathrm{L}^{-1}$ & $0.181-0.184$ & $0.082-0.087$ \\
\hline
\end{tabular}

(Table 1). This is explained on the basis that organic pollutants, and particularly phenolic compounds, are transferred from the oil phase to the water (hydrophilic phase) during the vertical centrifugation, whereas during the olives washing process, the level of organic contamination attained in the water (OWW) is much lower and phenolic species are negligible, only measured in case of fruit rupture in the recollection of the fruit or during the washing procedure [6]. The organic load in OWW stands normally below the limits for discharge on superficial suitable terrains. However, concentration values may exceed the established standards (Guadalquivir Hydrographical Confederation, 2006: COD < $1000 \mathrm{mg} \mathrm{O}_{2} \mathrm{~L}^{-1}$ ) depending mainly on the water flowrate employed in the olives washing machines during the fruit cleaning procedure.

2.2. Pretreatment of the Raw OMW and MOMW Effluents. In first place, both raw feedstocks were subjected to gridding (cut-size equal to $300 \mu \mathrm{m}$ ) with the primary objective of removing coarse particles. After this, a pretreatment procedure based on $\mathrm{pH}$-temperature flocculation, studied in previous works [21], was applied to the OMW and MOMW effluents. In this study, $\mathrm{pH}-\mathrm{T}$ flocculation process optimization was checked again at lab scale on the target feedstocks and finally conducted on a pilot scale.

Laboratory scale experiments were first carried out in order to find the best $\mathrm{pH}$ and temperature conditions for the flocculation process. OMW and MOMW samples $(200 \mathrm{~mL})$ were poured in beakers $(0.5 \mathrm{~L})$ fitted with magnetic stirring. Experiments at different $\mathrm{pH}$ values (ranging from 2 up to 7 ) and several temperature values $\left(15,25\right.$, and $\left.50^{\circ} \mathrm{C}\right)$ were performed. $\mathrm{HNO}_{3}(70 \% \mathrm{w} / \mathrm{w})$ and $\mathrm{NaOH}(1 \mathrm{~N})$ were used to reduce or increase the $\mathrm{pH}$ values of the feedstock, respectively. For all experiments, the same procedure was adopted: a short, initial high stirring rate mixing $(90 \mathrm{~s}, 1000 \mathrm{rpm})$ followed by slow stirring for a longer amount of time $(20 \mathrm{~min}$, $320 \mathrm{rpm}$ ). The initial strong mixing stage promotes uniform dispersion of the flocculant and particles collisions, whereas the following weak mixing ensures ideal conditions for the movement of the flocks in suspension, without destroying them. After that mixing was completely stopped, the sample was left to settle for 24 hours, and the mud was extracted from the bottom of the reactor and finally dried in order to calculate the sludge fraction and the fraction of clarified water $(\% \mathrm{v} / \mathrm{v})$. Additionally, total suspended solids (TSS) removal efficiency was measured in the clarified supernatant at the end of each experiment.
Once optimized, the $\mathrm{pH}$-T flocculation process was scaled up and conducted in a stirred batch reactor $(20 \mathrm{~L})$ provided with a turbine impeller stirrer and the achieved reduction of total phenols concentration (TPh), chemical oxygen demand (COD), and total suspended solids (TSS) were finally measured.

2.3. Lab-Made Production of the Ferromagnetic-Core Nanocatalyst. The possibilities of application of $\mathrm{TiO}_{2}$ are being investigated since the early 1970s after a pioneering work by Fujishima and Honda [22] and is nowadays a well-known and commercially used photocatalyst [23]. Nanocrystalline $\mathrm{TiO}_{2}$ immobilized on supporting materials such as glass, sand, or zeolite can improve the separation efficiency. Magnetic separation provides a very convenient approach for removing and recycling magnetic particles (such as magnetite, ferrite, and barium ferrite) by applying external magnetic fields. The incorporation of magnetic components into $\mathrm{TiO}_{2}$ nanoparticle-based catalysts may, therefore, enhance the separation and recovery of nanosized $\mathrm{TiO}_{2}$ [24]. Very recently, a large-scale synthesis of discrete and uniformly sized super paramagnetic $\mathrm{Fe}_{3} \mathrm{O}_{4} / \mathrm{SiO}_{2}$ was developed [25]. Reaction time, tetraethyl-orthosilicate (TEOS) $/ \mathrm{Fe}_{3} \mathrm{O}_{4}$ ratio, and hydrophilic $\mathrm{Fe}_{3} \mathrm{O}_{4}$ seeds concentration were found to be very important parameters in the control of silica shell thickness from $12.5 \mathrm{~nm}$ to $45 \mathrm{~nm}$ [26].

However, currently there is little literature on the synthesis of $\mathrm{Fe}_{3} \mathrm{O}_{4} / \mathrm{SiO}_{2} / \mathrm{TiO}_{2}$ core-shell nanoparticles and their photocatalytic properties. Gad-Allah et al. [27] reported the preparation of $\mathrm{Fe}_{3} \mathrm{O}_{4} / \mathrm{SiO}_{2} / \mathrm{TiO}_{2}$ nanocomposites. However, $\mathrm{Fe}_{3} \mathrm{O}_{4} / \mathrm{SiO}_{2} / \mathrm{TiO}_{2}$ core-shell nanoparticles were in the form of patches and not discrete nanoparticles; thus, these nanoparticles exhibited reduction of their surface area and photocatalytic properties. Abramson et al. [28] produced core-shellshell $\mathrm{Fe}_{3} \mathrm{O}_{4} / \mathrm{SiO}_{2} / \mathrm{TiO}_{2}$ nanoparticles of few tens nanometers by successively coating onto the magnetic nanoparticles a $\mathrm{SiO}_{2}$ layer and $\mathrm{a} \mathrm{TiO}_{2}$ layer, using sol-gel methods.

In this work, the production process of the photocatalyst was performed in three subsequent steps. Firstly, magnetite was produced by using a spinning disk reactor (SDR). This technology allows obtaining nanomaterial by chemical precipitation or sol-gel processes continuously. Two reactants were used: on the one side, an aqueous solution of $\mathrm{FeCl}_{3}, \mathrm{HCl}$, and $\mathrm{Na}_{2} \mathrm{SO}_{3}$ and on the other side, an aqueous solution of $\mathrm{NH}_{4} \mathrm{OH}$. As pointed out previously by De Caprariis et al. [29], the location of the feed points over the disk influences the precipitation outcome. In this case, the first reactant was fed at the center of the disk, whereas the second one was injected at $2 \mathrm{~cm}$ of distance. This permits producing magnetite with a modal particle size of $30 \mathrm{~nm}$. A scheme of the adopted spinning disk reactor is shown in Figure 2.

The second step consists of a coating of silica, performed by adding the dried magnetite particles to a TEOS-ethanol$\mathrm{NH}_{3}$ solution. The coated particles were then recovered back by magnets, gently dried at $80^{\circ} \mathrm{C}$, and calcinated at $450^{\circ} \mathrm{C}$.

Finally, the $\mathrm{TiO}_{2}$ coating was performed by pouring the silica-coated particles in a titanium tetraisopropoxideethanol solution and adding $\mathrm{H}_{2} \mathrm{O}_{2}$ dropwise to the solution 


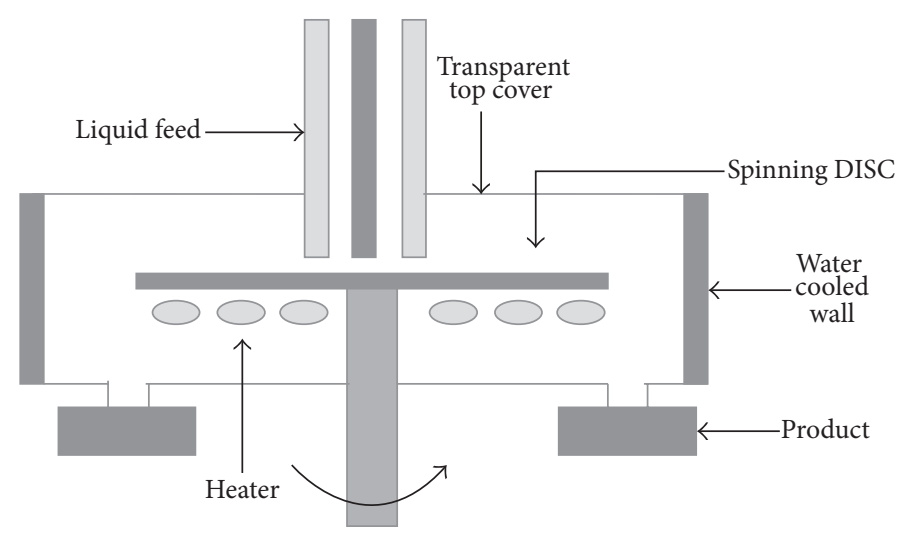

FIGURE 2: Scheme of the adopted rotating disk reactor [21, 29].

under strong mixing conditions. Again, the recovered particles were dried gently at $80^{\circ} \mathrm{C}$ and a final calcination at $450^{\circ} \mathrm{C}$ was performed.

\subsection{Characterization of the Lab-Made Photocatalyst. Parti-} cle size distribution (PSD) analysis was performed with a dynamic light scattering device (Plus90 nanosizer) supplied by Brookhaven. Determination of the presence of silicon and titanium atoms was conducted by means of an energydispersive X-ray diffraction (EDX) analysis. Transmission electron microscopy (TEM) was carried out with an Auriga Zeiss instrument to observe the overall morphology of the nanoparticles.

2.5. $\mathrm{TiO}_{2} / U V$ Photocatalytic Degradation of $\mathrm{OMW}$ and OWMW. $\mathrm{TiO}_{2} / \mathrm{UV}$ photocatalysis process was firstly optimized at lab scale on $200 \mathrm{~mL}$ samples of the supernatant of OMW and OWMW previously pretreated by $\mathrm{pH}-\mathrm{T}$ flocculation. Lab experiments were conducted in $0.5 \mathrm{~L}$ beakers with magnetic stirring at ambient temperature $\left(20 \pm 0.5^{\circ} \mathrm{C}\right)$ and medium agitation speed (500 rpm) during 2-4 hours under irradiation of an UV lamp (nominal power $45 \mathrm{~W}$, wavelength $365 \mathrm{~nm}$ ). The performance of the lab-made ferromagneticcore photocatalytic nanoparticles was contrasted with that of commercial $\mathrm{TiO}_{2}$ P-25 catalyst provided by Degussa for comparison purposes. Different catalysts dosages $(0.5,1,3$, and $9 \mathrm{~g} \mathrm{~L}^{-1}$ for both catalysts, plus $20 \mathrm{~g} \mathrm{~L}^{-1}$ for the commercial Degussa P-25) were tested and reduction of the COD values was followed during the course of the experiments. Laboratory scale experiments aimed to find the best $\mathrm{TiO}_{2}$ catalyst and its optimal initial dosage.

Once lab-scale optimization was accomplished, the photocatalysis process was carried out in an agitated batch reactor $(8 \mathrm{~L})$, provided with an UV lamp on top and a turbine impeller stirrer. Achieved reduction of COD, total phenols (TPh) concentration, and total suspended solids (TSS) were checked at the end of the pilot scale process.

2.6. Analytical Methods. Chemical oxygen demand (COD), total phenols (TPh), total suspended solids (TSS), electroconductivity (EC), and $\mathrm{pH}$ were measured following standard methods (Greenberg, 1992). All analytical methods were applied in triplicate with analytical-grade reagents, including $70 \%$ (w/w) $\mathrm{HNO}_{3}, 98 \%$ (w/w) $\mathrm{NaOH}, 98 \%$ (w/w) $\mathrm{Na}_{2} \mathrm{SO}_{3}$, $30 \%(w / w) \mathrm{NH}_{4} \mathrm{OH}, 37 \%$ (w/w) $\mathrm{HCl}$, and 30\% (w/w) $\mathrm{FeCl}_{3}$, supplied by Panreac.

\section{Results and Discussion}

3.1. Pretreatment of OMW by $\mathrm{pH}-\mathrm{T}$ Flocculation. Figure 3 shows the optimal operating conditions found at lab scale for the $\mathrm{pH}-\mathrm{T}$ flocculation process, taking TSS reduction in supernatant as key parameter, suggested working at temperatures of $25 \pm 0.5^{\circ} \mathrm{C}$ and $\mathrm{pH}$ values equal to $2.5 \pm 0.25$ (by adding $0.55 \pm 0.05 \% \mathrm{v} / \mathrm{v} 70 \% \mathrm{HNO}_{3}$ ). OMW is considered to be closely related to humic compounds because it is dark colored, contains phenols, and shares some of the properties of humic substances. Jin et al. [30] studies on particle size distribution (PSD) of humic acid by dynamic light scattering confirmed higher hydrodynamic diameters at lower temperature values, predominantly in form of submicron aggregates and a small fraction of supramicron aggregates, due to minor solubility of the organic matter. Furthermore, at low $\mathrm{pH}$ values $(\mathrm{pH}<4)$, these macromolecules are protonated and thus neutrally charged. The absence of electrostatic repulsion among the humic macromolecules thus enhances molecular aggregation. Similar trends with regard to natural organic matter (NOM) macromolecules were observed by Hong and Elimelech [31].

Upon those operating conditions, the final reduction values achieved at the end of the pilot scale $\mathrm{pH}-\mathrm{T}$ flocculation process were equal to $72.5 \% \mathrm{TSS}, 12.6 \% \mathrm{COD}$, and $5.0 \% \mathrm{TPh}$, with a recovery of up to $87.5 \% \mathrm{v} / \mathrm{v}$ of the clarified water which means a resultant $12.5 \% \mathrm{v} / \mathrm{v}$ of sludge. In a similar way, for the MOMW effluent, these results were equal to $93.4 \%$ TSS, $14.3 \% \mathrm{COD}$, and 5.2\% TPh reduction efficiencies. In this case, a final recovery of up to $90.2 \% \mathrm{v} / \mathrm{v}$ of the clarified supernatant was accomplished, that is leading to a resultant $9.8 \% \mathrm{v} / \mathrm{v}$ of sludge. The $\mathrm{pH}-\mathrm{T}$ coagulation-flocculation process seems to be a cost-effective pretreatment for the removal of the TSS concentration from OMW and MOMW, particularly if compared to current coagulation-flocculation processes with 

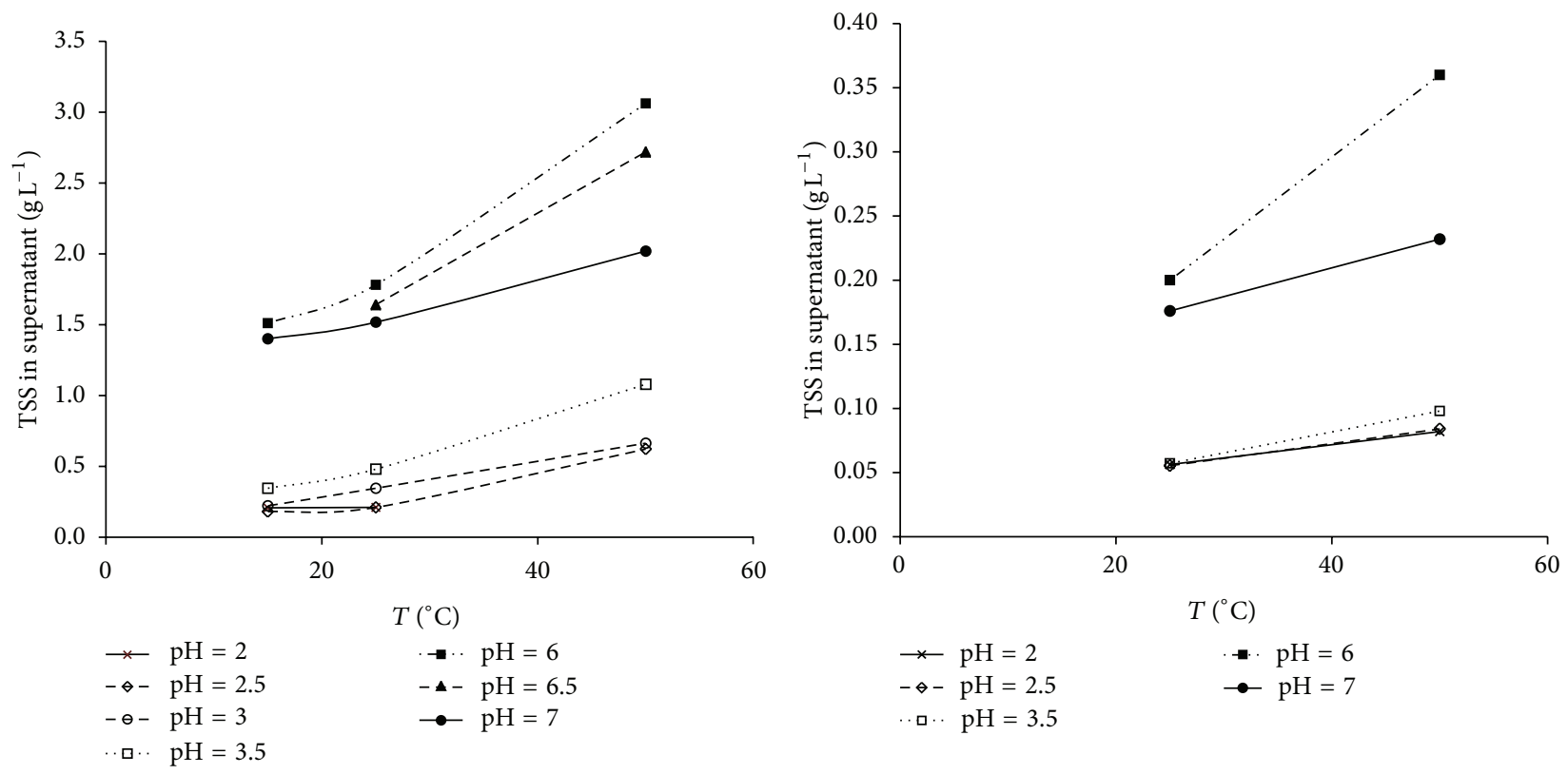

FIGURE 3: Lab-scale results of pH-T flocculation process on OMW (left caption) and MOMW (right capt.).

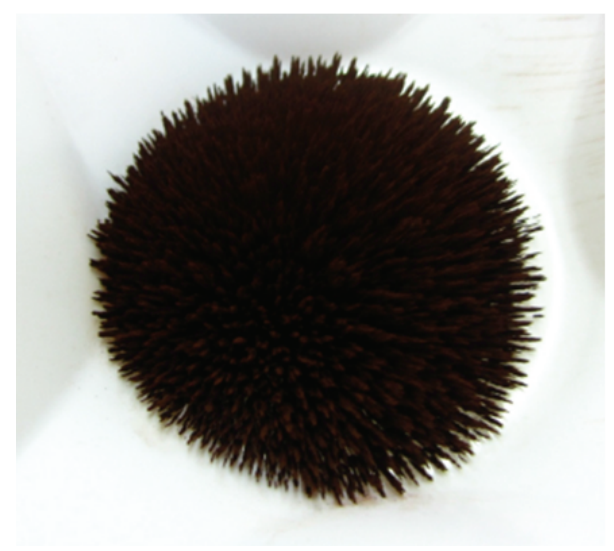

Figure 4: Photography of the ferromagnetic photocatalytic nanoparticles.

commercial flocculants, which may lead in our experience to lower efficiency values at higher costs.

3.2. Characterization of the Lab-Made Photocatalyst. The lab-made nanocatalyst (Figure 4) is internally composed of a ferromagnetic core $\left(\gamma-\mathrm{Fe}_{2} \mathrm{O}_{3}\right.$, modal particle size of $30 \mathrm{~nm}$ ) on which two subsequent layers of silica and titania are attached $\left(\gamma \mathrm{Fe}_{2} \mathrm{O}_{3} / \mathrm{SiO}_{2} / \mathrm{TiO}_{2}\right)$. Energy-dispersive X-ray diffraction spectrum (EDX) of the ferromagnetic nanoparticles is given in Figure 5, whereas transmission electron microscopy (TEM) microphotographs and particle size distribution (PSD) analysis of the obtained ferromagnetic-core nanoparticles are shown in Figure 6. TEM image of the nanoparticles shows regular overall morphology. The final mean particle size of the nanopowder was equal to $79 \mathrm{~nm}$ with very uniform, homogeneous, and pure anatase $\mathrm{TiO}_{2}$ phase $(100 \%)$ with some traces of brookite. EDX analysis, performed to determine the elemental composition of the obtained composite nanoparticles, shows that the obtained nanopowder consisted of $\mathrm{Fe}, \mathrm{Si}$, and $\mathrm{Ti}$, verifying the presence of both silica and $\mathrm{TiO}_{2}$ layers.

3.3. Photocatalytic Degradation of OMW. The evolution of the organic matter (COD) removal from OMW during the lab-scale $\mathrm{UV} / \mathrm{TiO}_{2}$ process with both catalysts and feedstocks is reported in Figure 7. A semilogarithmic fitting curve was applied for interpolating the COD reduction during operation time as follows:

$$
\Delta \mathrm{COD}=B \cdot \ln (t)+\Delta \mathrm{COD}(0.5),
$$

where $B\left(\mathrm{~g} \mathrm{~L}^{-1} \mathrm{~h}^{-1}\right)$ indicates the rate of degradation of the organic matter during the photocatalysis experiments and $\triangle \mathrm{COD}(0.5)\left(\mathrm{g} \mathrm{L}^{-1}\right)$ makes reference to the initial abatement of organic pollutants. Overall results of the lab-scale $\mathrm{UV} / \mathrm{TiO}_{2}$ tests are reported in Table 2.

The laboratory-made ferromagnetic-core photocatalyst was found to provide slightly higher COD removal than the commercial one for both feedstocks upon lower initial catalyst dosages, equal to $1 \mathrm{~g} \mathrm{~L}^{-1}$ and $0.5 \mathrm{~g} \mathrm{~L}^{-1}$ for the treatment of OMW and MOMW, respectively. This is supported by the $100 \%$ anatase $\mathrm{TiO}_{2}$ phase of the lab-made ferromagnetic catalyst. Among the three crystalline phases of $\mathrm{TiO}_{2}$, called anatase, rutile, and brookite, the former is the most active under UV irradiation, strongly dependent on the particle size and habit too [32]. The sol-gel process performed in this work for the fabrication of the ferromagnetic core catalyst leads to the formation of homogeneous, pure, and very uniform particles (Figure 6(b)) [29]. Mixed-phase submicron particles such as commercial Degussa P-25, consisting of 70\% anatase and $30 \%$ rutile, seem to provide less effective catalytic action. 


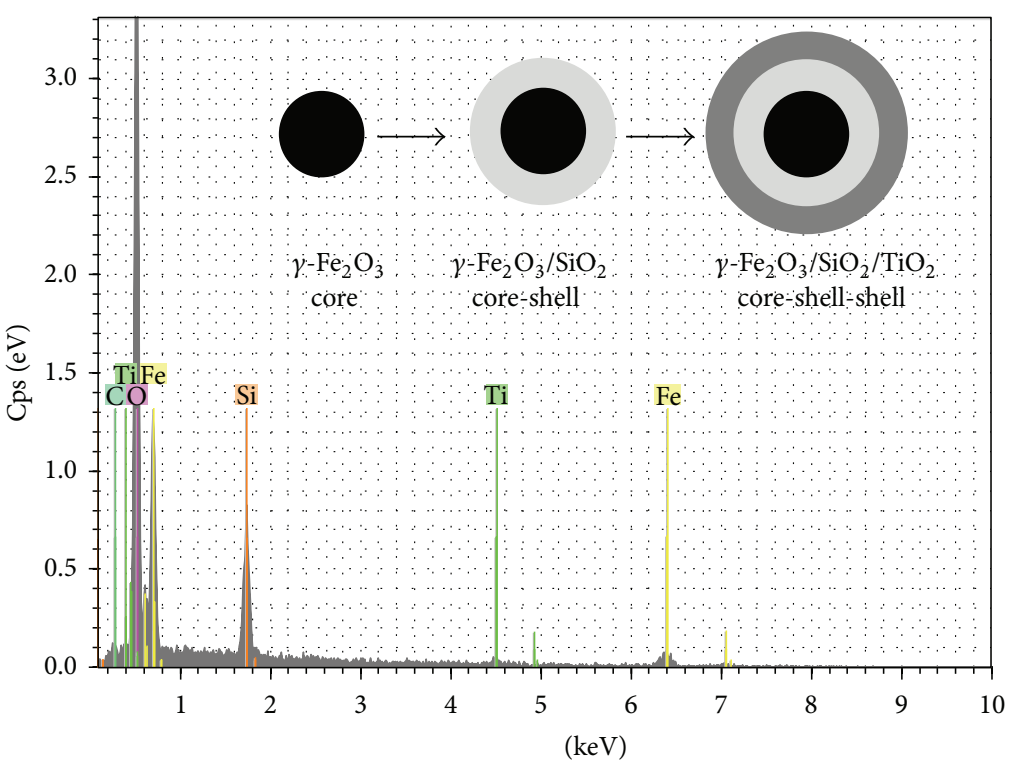

FIGURE 5: Energy-dispersive X-ray diffraction spectrum (EDX) of the ferromagnetic nanoparticles.

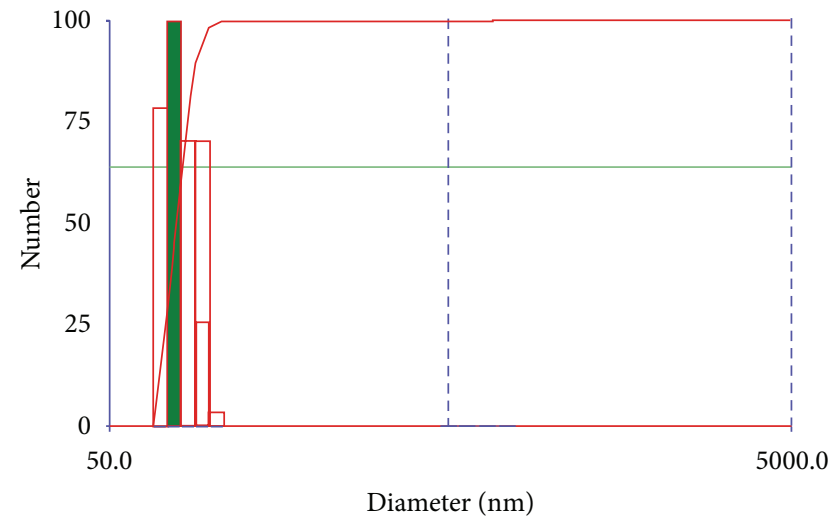

Rel. Num. $=100.00$ Cum. Num. $=64.15$ Diam. $(\mathrm{nm})=79.29$

(a)

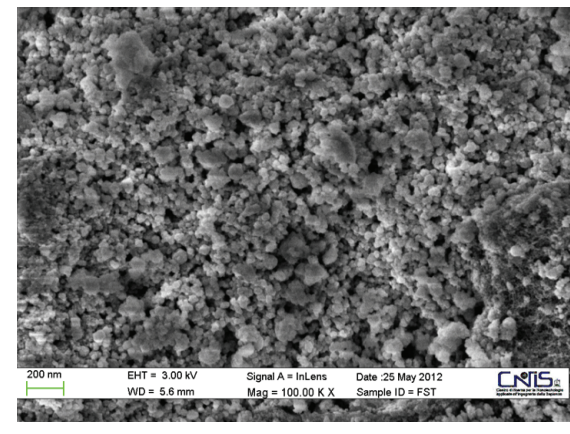

(b)

FIGURE 6: Particle size distribution measured by the nanosizer (a) and TEM photograph (b) of the final ferromagnetic catalyst particles.

Moreover, significantly higher organic matter removal efficiency was observed for the MOMW effluent than that for OMW upon the optimal catalyst dosage, $58.4 \%$ for the former in contrast with $21.4 \%$ for the latter (Table 2). Also, adding large quantities of titania to the wastewater leads to poorer results. Both effects are narrowly connected to hindrance to deep penetration of UV light as a result of the opacity of the solutions, due to the major organic pollutants load or to the excessive nanocatalyst concentration, respectively, which in turn impedes efficient activation of the catalyst. A guided focus on Figure 7 permits to notice that no significant increase of the COD removal efficiencies was observed beyond a residence time $(\tau)$ of 3 hours for OMW, whereas lower residence time was needed in the case of MOMW, $\tau=$ $2 \mathrm{~h}$.

Finally, $\mathrm{UV} / \mathrm{TiO}_{2}$ photocatalysis process was scaledup. The physicochemical composition of both OMW and
MOMW exiting each pilot scale treatment stage is given in Table 3. By adopting the optimal conditions at pilot scale, $23.4 \% \mathrm{COD}, 19.2 \% \mathrm{TPh}$, and $28.1 \%$ TSS were efficiently removed at the end of $\mathrm{UV} / \mathrm{TiO}_{2}$ process for OMW, whereas 58.3\% COD, 27.5\% TPh, and 25.0\% TSS for MOMW.

Again at lab scale, not only sensibly higher COD removal efficiency was noted (23.4\% versus $58.3 \%$ ) but also phenolic compounds (TPh) abatement (19.2\% versus $27.5 \%)$ for MOMW if compared with OMW, upon the optimized operating conditions, due to more efficient activation of the nanocatalyst owed to deeper penetration of UV light in less opaque medium.

The novel prepared lab-made titania ferromagnetic-core photocatalyst $\left(\gamma-\mathrm{Fe}_{2} \mathrm{O}_{3} / \mathrm{SiO}_{2} / \mathrm{TiO}_{2}\right)$ was developed with the goal of being able to be whether recovered back from the wastewater stream by a magnetic trap and reused or even fixed to the photocatalysis reactor, giving a solution to the 


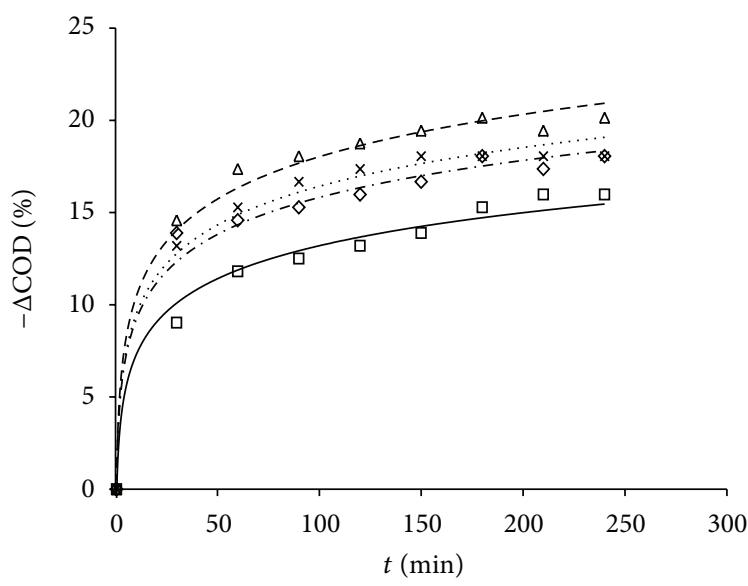

(a)

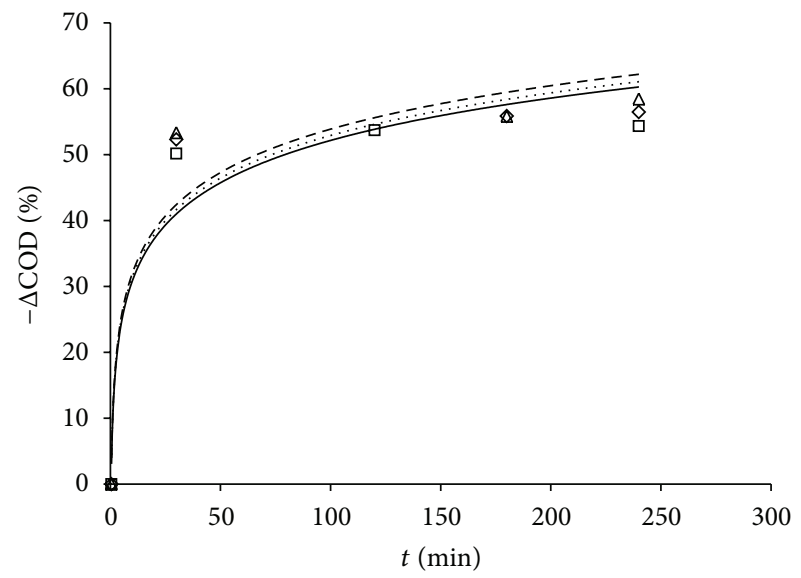

$\left(\mathrm{a}^{\prime}\right)$

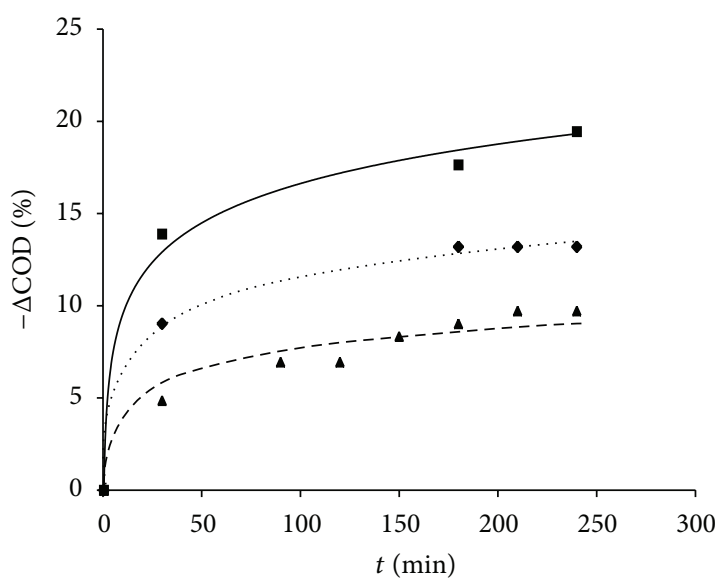

(b)

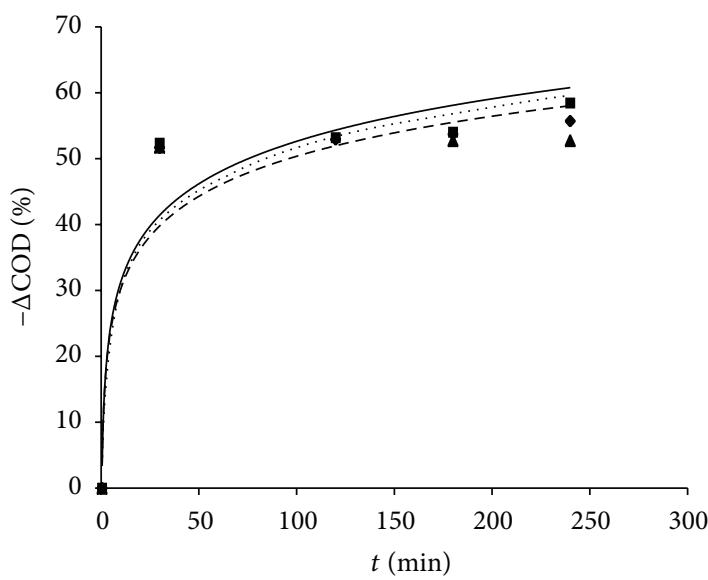

$\left(\mathrm{b}^{\prime}\right)$

Figure 7: Results withdrawn from $\mathrm{UV} / \mathrm{TiO}_{2}$ photocatalysis experiments on lab scale with OMW: commercial Degussa P-25 (a): $\square=1 \mathrm{~g} / \mathrm{L}, \diamond$ $=3 \mathrm{~g} / \mathrm{L}, \Delta=9 \mathrm{~g} / \mathrm{L}, \mathrm{x}=20 \mathrm{~g} / \mathrm{L}$; lab-made ferromagnetic-core nanopowder $(\mathrm{b}): \boldsymbol{\|}=1 \mathrm{~g} / \mathrm{L}, \downarrow=3 \mathrm{~g} / \mathrm{L}, \boldsymbol{\Delta}=9 \mathrm{~g} / \mathrm{L} ; \mathrm{MOMW}:$ Degussa P-25 (a'): $\square=$ $1 \mathrm{~g} / \mathrm{L}, \diamond=3 \mathrm{~g} / \mathrm{L}, \Delta=9 \mathrm{~g} / \mathrm{L}$; lab-made ferromagnetic-core nanopowder $\left(\mathrm{b}^{\prime}\right): \mathbf{m}=0.5 \mathrm{~g} / \mathrm{L}, \downarrow=1 \mathrm{~g} / \mathrm{L}, \mathbf{\Delta}=3 \mathrm{~g} / \mathrm{L}$.

TABLE 2: COD reduction in OMW and MOMW after lab-scale $\mathrm{UV} / \mathrm{TiO}_{2}$ photocatalysis.

\begin{tabular}{|c|c|c|c|c|c|c|}
\hline Raw effluent & Catalyst type & $\begin{array}{l}\text { Catalyst dosage } \\
\mathrm{g} \mathrm{L}^{-1}\end{array}$ & $\begin{array}{c}\mathrm{COD}_{\text {final }} \\
\mathrm{g} \mathrm{L}^{-1}\end{array}$ & $\begin{array}{c}-\Delta \mathrm{COD}_{4 \mathrm{~h}} \\
\%\end{array}$ & $\begin{array}{c}\Delta \mathrm{COD}^{(0.5)} \\
\mathrm{g} \mathrm{L}^{-1}\end{array}$ & $\begin{array}{c}B \\
\mathrm{~g} \mathrm{~L}^{-1} \mathrm{~h}^{-1}\end{array}$ \\
\hline \multirow{7}{*}{$\mathrm{OMW}\left(\mathrm{COD}_{\text {initial }} 14.5 \mathrm{~g} / \mathrm{L}\right)$} & \multirow{4}{*}{ Degussa P-25 } & 1 & 12.1 & 16.5 & 1.3 & 2.6 \\
\hline & & 3 & 11.8 & 18.6 & 2.5 & 2.9 \\
\hline & & 9 & 11.5 & 20.7 & 2.8 & 3.3 \\
\hline & & 20 & 11.8 & 18.6 & 2.7 & 3.0 \\
\hline & \multirow{3}{*}{ Ferromag. $\mathrm{TiO}_{2}$} & 1 & 11.4 & 21.4 & 2.5 & 3.2 \\
\hline & & 3 & 12.5 & 13.3 & 1.6 & 2.2 \\
\hline & & 9 & 13.1 & 10.3 & 0.6 & 1.6 \\
\hline \multirow{6}{*}{$\mathrm{MOMW}\left(\mathrm{COD}_{\text {initial }} 3.6 \mathrm{~g} / \mathrm{L}\right)$} & \multirow{3}{*}{ Degussa P-25 } & 1 & 1.7 & 54.3 & 10.1 & 9.2 \\
\hline & & 3 & 1.6 & 56.5 & 10.0 & 9.3 \\
\hline & & 9 & 1.5 & 57.0 & 10.1 & 9.5 \\
\hline & \multirow{3}{*}{ Ferromag. $\mathrm{TiO}_{2}$} & 0.5 & 1.5 & 58.4 & 9.8 & 9.3 \\
\hline & & 1 & 1.6 & 55.7 & 10.0 & 9.1 \\
\hline & & 3 & 1.7 & 52.7 & 9.9 & 8.7 \\
\hline
\end{tabular}


TABLE 3: Physicochemical composition of OMW and MOMW after flocculation (F) and photocatalytic (PC) degradation on pilot scale.

\begin{tabular}{lcccc}
\hline Feedstock & OMW-F & $\begin{array}{c}\text { OMW-F } \\
\text { and PC }\end{array}$ & MOMW-F & $\begin{array}{c}\text { MOMW-F } \\
\text { and PC }\end{array}$ \\
\hline $\mathrm{pH}$ & 2.5 & 2.9 & 2.5 & 3.1 \\
$\mathrm{EC}, \mathrm{mS} \mathrm{cm}^{-1}$ & 1.7 & 1.8 & 1.5 & 1.5 \\
$\mathrm{TSS}, \mathrm{g} \mathrm{L}^{-1}$ & 1.6 & 1.2 & 0.4 & 0.3 \\
$\mathrm{COD}_{\mathrm{g} \mathrm{L}}^{-1}$ & 14.5 & 11.1 & 3.6 & 1.5 \\
$\mathrm{TPh}_{\mathrm{mg} \mathrm{L}}$ & 172 & 139 & 82.5 & 59.8 \\
\hline
\end{tabular}

problem of the recovery of the catalyst and thus considerably enhancing the cost-effectiveness of the olive mill effluents reclamation process.

Furthermore, the overall efficiency of the process by treating the mixture of the OMW stream mixed with the OWW effluent (MOMW) triggers up to $91.0 \%$ of COD removal, leading to final COD values in the treated water below $1.5 \mathrm{~g} \mathrm{~L}^{-1}$, in contrast with the barely $33.2 \% \mathrm{COD}$ removal efficiency achieved for the treatment of the OMW separately.

\section{Conclusions}

According to the results obtained in this investigation, the photocatalytic degradation process is an alternative with high possibility to be used in the treatment of OMW from twophase continuous centrifugation process. The easy recovery and reuse of photocatalyst minimizes the operating costs of the treatment process. The novel photocatalyst used in this work offers good results in comparison with other commercial catalysts as Degussa P-25. The photodegradation process implies high reduction of the percentages of COD, total phenols, and total suspended solids. At pilot scale, $23.4 \% \mathrm{COD}_{\text {removal }}, 19.2 \%$ total phenols removal $_{\text {, }}$, and $28.1 \%$ total suspended solids removal $_{\text {were }}$ registered at the end of the $\mathrm{UV} / \mathrm{TiO}_{2}$ process for OMW upon a residence time $(\tau)$ equal to 3 hours, whereas $58.3 \% \mathrm{COD}_{\text {removal }}, 27.5 \%$ total phenols removal , and $25.0 \%$ total suspended solids removal $_{\text {for }}$ MOMW upon $\tau=2 \mathrm{~h}$. Also, before the $\mathrm{UV} / \mathrm{TiO}_{2}$ reaction a $\mathrm{pH}-\mathrm{T}$ flocculation operation as a pretreatment was realized. The overall efficiency of the treatment process for MOMW was up to $91 \%$ of $\mathrm{COD}_{\text {removal }}$, in contrast with $33.2 \%$ of $\mathrm{COD}_{\text {removal }}$ for OMW.

\section{Conflict of Interests}

The authors declare that they have no conflict of interests.

\section{Acknowledgments}

Funding by the European project PHOTOMEM (Contract no. FP7-SME-2011, Grant 262470) and the European project ETOILE (Contract no. FP7-SME-2007-1, Grant 222331) is acknowledged. The Spanish Ministry of Science and Innovation is also gratefully acknowledged for having funded the Projects CTQ2007-66178 and CTQ2010-21411.

\section{References}

[1] J. C. Crittenden, R. R. Trussell, D. W. Hand, K. J. Howe, and G. Tchobanoglous, Water Treatment: Principles and Design, John Wiley \& Sons, Hoboken, NJ, USA, 2nd edition, 2005.

[2] S. Tieng, A. Kanaev, and K. Chhor, "New homogeneously doped $\mathrm{Fe}(\mathrm{III})-\mathrm{TiO}_{2}$ photocatalyst for gaseous pollutant degradation," Applied Catalysis A, vol. 399, no. 1-2, pp. 191-197, 2011.

[3] D. Chen, Z. Jiang, J. Geng, Q. Wang, and D. Yang, "Carbon and nitrogen co-doped $\mathrm{TiO}_{2}$ with enhanced visible-light photocatalytic activity," Industrial and Engineering Chemistry Research, vol. 46, no. 9, pp. 2741-2746, 2007.

[4] D. Chatterjee and S. Dasgupta, "Visible light induced photocatalytic degradation of organic pollutants," Journal of Photochemistry and Photobiology C, vol. 6, no. 2-3, pp. 186-205, 2005.

[5] L. M. Nieto, G. Hodaifa, S. Rodríguez, J. A. Giménez, and J. Ochando, "Degradation of organic matter in olive-oil mill wastewater through homogeneous Fenton-like reaction," Chemical Engineering Journal, vol. 173, no. 2, pp. 503-510, 2011.

[6] G. Hodaifa, M. E. Martínez, and S. Sánchez, "Use of industrial wastewater from olive-oil extraction for biomass production of Scenedesmus obliquus," Bioresource Technology, vol. 99, no. 5, pp. 1111-1117, 2008.

[7] M. Niaounakis and C. P. Halvadakis, Olive Processing Waste Management Literature Review and Patent Survey, vol. 5 of Waste Management Series, Elsevier, Amsterdam, The Netherlands, 2nd edition, 2006.

[8] H. Inan, A. Dimoglo, H. Şimşek, and M. Karpuzcu, "Olive oil mill wastewater treatment by means of electro-coagulation," Separation and Purification Technology, vol. 36, no. 1, pp. 23-31, 2004.

[9] Ü. T. Ün, S. Uğur, A. S. Koparal, and Ü. B. Öğütveren, "Electrocoagulation of olive mill wastewaters," Separation and Purification Technology, vol. 52, no. 1, pp. 136-141, 2006.

[10] S. Khoufi, F. Aloui, and S. Sayadi, "Treatment of olive oil mill wastewater by combined process electro-Fenton reaction and anaerobic digestion," Water Research, vol. 40, no. 10, pp. 20072016, 2006

[11] P. Cañizares, L. Martínez, R. Paz, C. Sáez, J. Lobato, and M. A. Rodrigo, "Treatment of Fenton-refractory olive oil mill wastes by electrochemical oxidation with boron-doped diamond anodes," Journal of Chemical Technology and Biotechnology, vol. 81, no. 8, pp. 1331-1337, 2006.

[12] L. Rizzo, G. Lofrano, M. Grassi, and V. Belgiorno, "Pretreatment of olive mill wastewater by chitosan coagulation and advanced oxidation processes," Separation and Purification Technology, vol. 63, no. 3, pp. 648-653, 2008.

[13] U. T. Un, U. Altay, A. S. Koparal, and U. B. Ogutveren, "Complete treatment of olive mill wastewaters by electrooxidation," Chemical Engineering Journal, vol. 139, no. 3, pp. 445-452, 2008.

[14] W. K. Lafi, B. Shannak, M. Al-Shannag, Z. Al-Anber, and M. Al-Hasan, "Treatment of olive mill wastewater by combined advanced oxidation and biodegradation," Separation and Purification Technology, vol. 70, no. 2, pp. 141-146, 2009.

[15] P. Cañizares, R. Paz, C. Sáez, and M. A. Rodrigo, "Costs of the electrochemical oxidation of wastewaters: a comparison with ozonation and Fenton oxidation processes," Journal of Environmental Management, vol. 90, no. 1, pp. 410-420, 2009.

[16] P. Grafias, N. P. Xekoukoulotakis, D. Mantzavinos, and E. Diamadopoulos, "Pilot treatment of olive pomace leachate by 
vertical-flow constructed wetland and electrochemical oxidation: an efficient hybrid process," Water Research, vol. 44, no. 9, pp. 2773-2780, 2010.

[17] N. Papastefanakis, D. Mantzavinos, and A. Katsaounis, "DSA electrochemical treatment of olive mill wastewater on $\mathrm{Ti} / \mathrm{RuO}_{2}$ anode," Journal of Applied Electrochemistry, vol. 40, no. 4, pp. 729-737, 2010.

[18] P. Paraskeva and E. Diamadopoulos, "Technologies for olive mill wastewater (OMW) treatment: a review," Journal of Chemical Technology and Biotechnology, vol. 81, no. 9, pp. 1475-1485, 2006.

[19] B. De Caprariis, M. Di Rita, M. Stoller, N. Verdone, and A. Chianese, "Reaction-precipitation by a spinning disc reactor: influence of hydrodynamics on nanoparticles production," Chemical Engineering Science, vol. 76, pp. 73-80, 2012.

[20] O. Sacco, M. Stoller, V. Vaiano, P. Ciambelli, A. Chianese, and D. Sannino, "Photocatalytic degradation of organic dyes under visible light on n-doped photocatalysts," International Journal Photoenergy, vol. 2012, Article ID 626759, 8 pages, 2012.

[21] J. M. Ochando-Pulido, M. Stoller, M. Bravi, A. MartinezFerez, and A. Chianese, "Batch membrane treatment of olive vegetation wastewater from two-phase olive oil production process by threshold flux based methods," Separation Purification Technology, vol. 101, pp. 34-41, 2012.

[22] A. Fujishima and K. Honda, "Electrochemical photolysis of water at a semiconductor electrode," Nature, vol. 238, no. 5358, pp. 37-38, 1972.

[23] V. Tyrpekl, J. P. Vejpravová, A. G. Roca, N. Murafa, L. Szatmary, and D. Nižňanský, "Magnetically separable photocatalytic composite $\gamma-\mathrm{Fe}_{2} \mathrm{O}_{3} @ \mathrm{TiO}_{2}$ synthesized by heterogeneous precipitation," Applied Surface Science, vol. 257, no. 11, pp. 4844-4848, 2011.

[24] M. Ye, Q. Zhang, Y. Hu et al., "Magnetically recoverable coreshell nanocomposites with enhanced photocatalytic activity," Chemistry, vol. 16, pp. 6243-6250, 2010.

[25] A. Schätz, M. Hager, and O. Reiser, "Cu(II)-azabis(oxazoline)complexes immobilized on superparamagnetic magnetite@ silica-nanoparticles: a highly selective and recyclable catalyst for the kinetic resolution of 1,2-diols," Advanced Functional Materials, vol. 19, no. 13, pp. 2109-2115, 2009.

[26] C. Hui, C. Shen, J. Tian et al., "Core-shell $\mathrm{Fe}_{3} \mathrm{O}_{4} @ \mathrm{SiO}_{2}$ nanoparticles synthesized with well-dispersed hydrophilic $\mathrm{Fe}_{3} \mathrm{O}_{4}$ seeds," Nanoscale, vol. 3, no. 2, pp. 701-705, 2011.

[27] T. A. Gad-Allah, S. Kato, S. Satokawa, and T. Kojima, "Treatment of synthetic dyes wastewater utilizing a magnetically separable photocatalyst $\left(\mathrm{TiO}_{2} / \mathrm{SiO}_{2} / \mathrm{Fe}_{3} \mathrm{O}_{4}\right)$ : parametric and kinetic studies," Desalination, vol. 244, no. 1-3, pp. 1-11, 2009.

[28] S. Abramson, L. Srithammavanh, J.-M. Siaugue, O. Horner, X. $\mathrm{Xu}$, and V. Cabuil, "Nanometric core-shell-shell $\gamma$ - $\mathrm{Fe}_{2} \mathrm{O}_{3} / \mathrm{SiO}_{2} /$ $\mathrm{TiO}_{2}$ particles," Journal of Nanoparticle Research, vol. 11, no. 2, pp. 459-465, 2009.

[29] B. De Caprariis, M. Di Rita, M. Stoller, N. Verdone, and A. Chianese, "Reaction-precipitation by a spinning disc reactor: influence of hydrodynamics on nanoparticles production," Chemical Engineering Science, vol. 76, pp. 73-80, 2012.

[30] X. Jin, A. Jawor, S. Kim, and E. M. V. Hoek, "Effects of feed water temperature on separation performance and organic fouling of brackish water RO membranes," Desalination, vol. 238, no. 1-3, pp. 346-359, 2009.

[31] S. Hong and M. Elimelech, "Chemical and physical aspects of natural organic matter (NOM) fouling of nanofiltration membranes," Journal of Membrane Science, vol. 132, no. 2, pp. 159-181, 1997.

[32] G. Li, L. Li, J. Boerio-Goates, and B. F. Woodfield, "High purity anatase $\mathrm{TiO}_{2}$ nanocrystals: near room-temperature synthesis, grain growth kinetics, and surface hydration chemistry," Journal of the American Chemical Society, vol. 127, no. 24, pp. 86598666, 2005. 

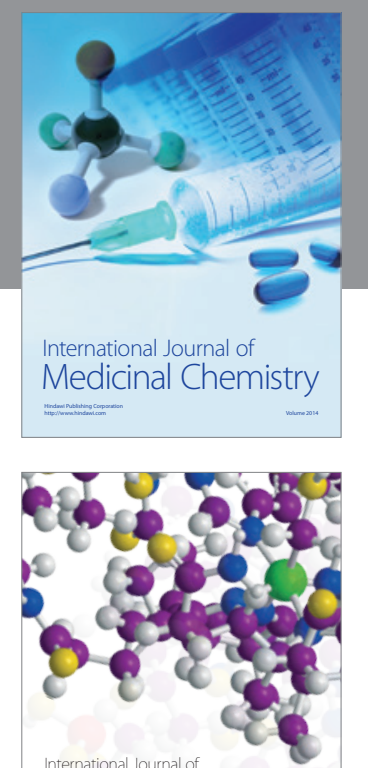

\section{Carbohydrate} Chemistry

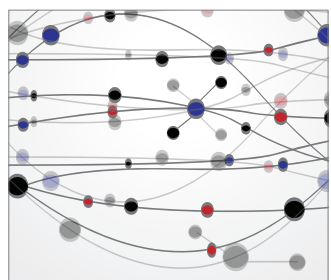

The Scientific World Journal
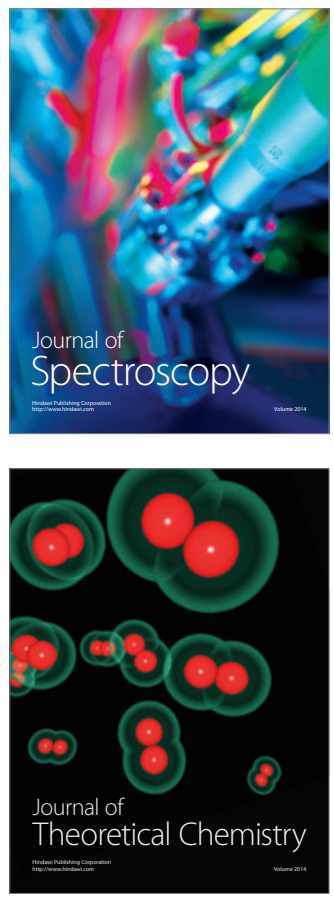
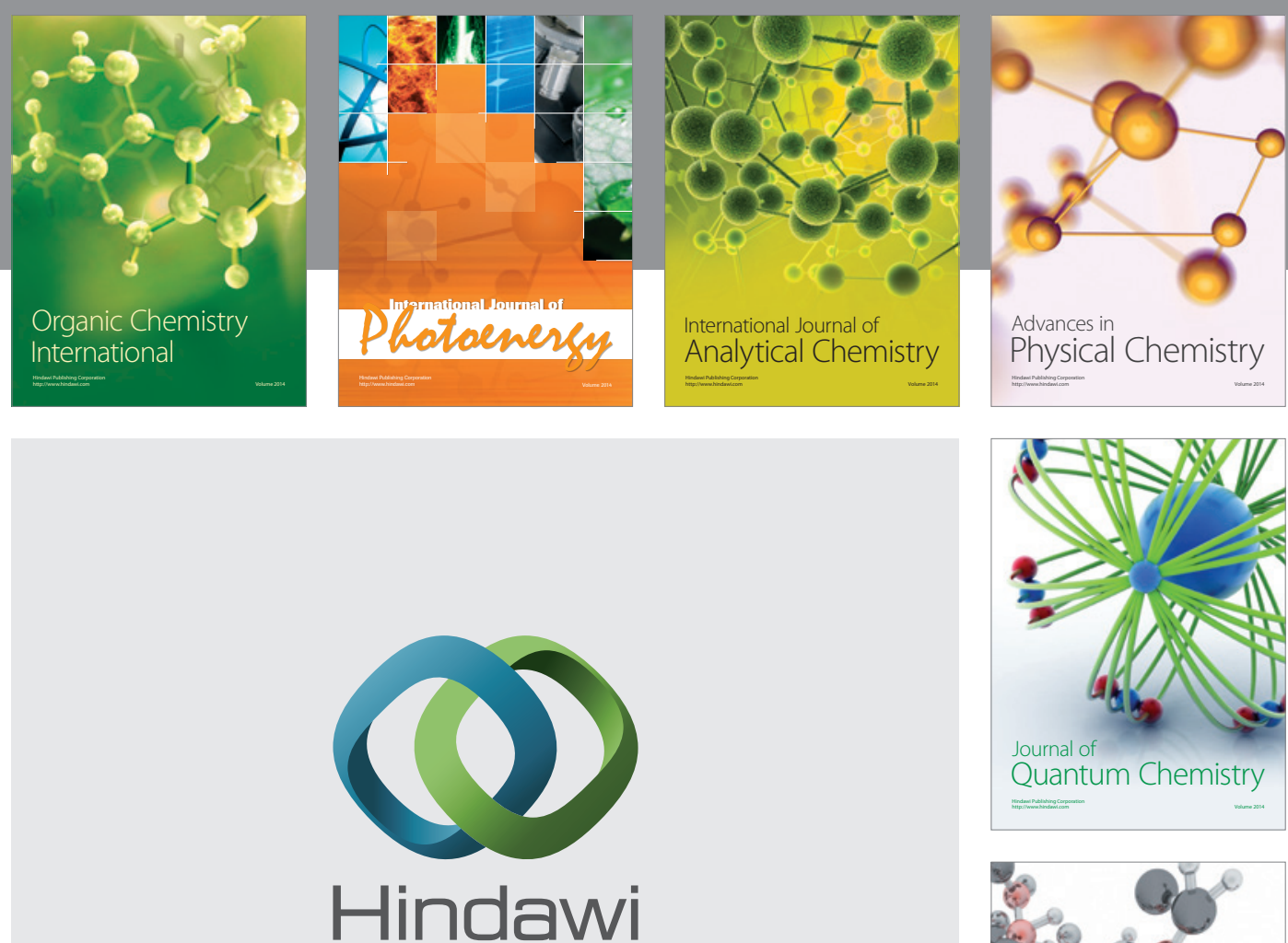

Submit your manuscripts at

http://www.hindawi.com

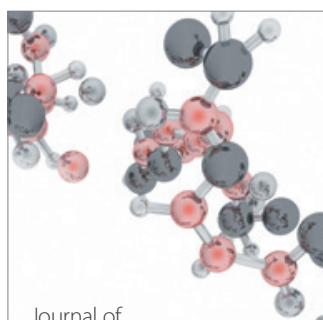

Analytical Methods

in Chemistry

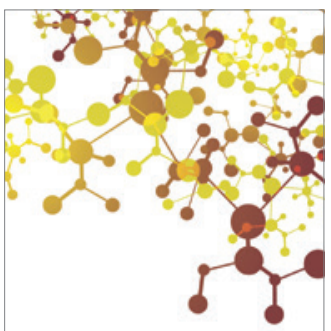

Journal of

Applied Chemistry

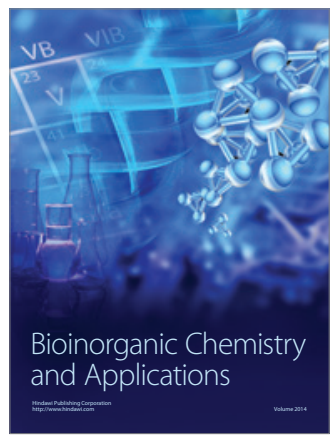

Inorganic Chemistry
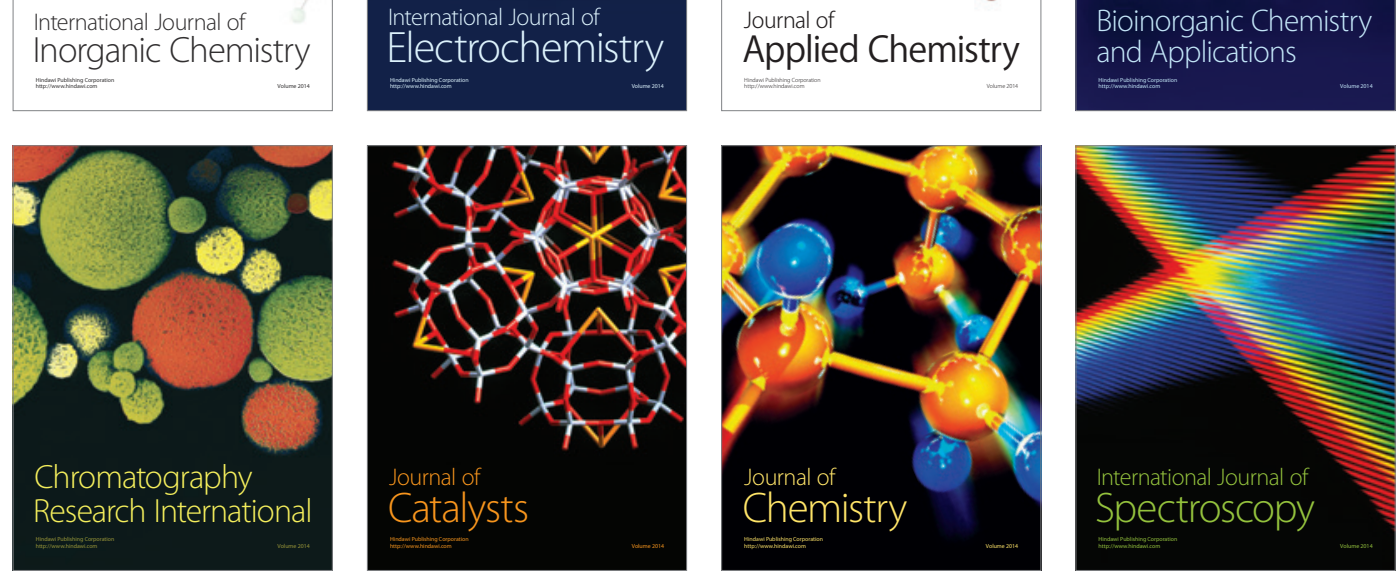